\title{
Moisture Absorption Evolution of Gfrp Laminates Subjected To Different Environmental Conditions
}

\author{
P.Sampath Rao ${ }^{1}$, Dr. M.Manzoor Hussain ${ }^{2}$, R.Kishore ${ }^{3}$ \\ ${ }^{I}$ Research scholar JNT University Hyderabad. Mechanical Engineering Department Vijay Rural Eng. College, \\ Nizamabad A.P.INDIA \\ ${ }^{2}$ Professor, Mechanical Engineering Department JNT University Hyderabad. A.P.INDIA \\ ${ }^{3}$ Asst. Professor Mechanical Engineering Department Vijay Rural Eng. College, Nizamabad
}

\begin{abstract}
Fibre composites are being used in various applications from aerospace, military, marine boats and submarine to renewable energy generation. Higher energy demands across the developed and growing world for the usage and replacement of conventional materials with polymer composite materials for engineering applications which is always questioned by the end user, unless the research oriented reliable supporting certification is made available. The reinforcement materials are highly hygroscopic, the matrix material provides protection to the reinforcement. When the parts made of composite materials are exposed to environment, water molecules travel along the reinforcement and cause damage to the interfacial bonding, further the performance of the composite laminate get effected. In this scenario, the investigation related to this aspect requires quantitative assessment which is carried out with accelerated simulation of the real time situation to provide a scope to chacterization of Glass fibre reinforced polymer composite (GFRP) laminates subjected to variable environmental conditions. This investigation was to study the effect on weight gain and mechanical property of GFRP laminate subjected to different environmental conditions. The test results reviled that remarkable reduction in tensile property and moisture absorption for samples in water absorbed more moisture than $\mathrm{NaOH}$ and salt water.
\end{abstract}

Keywords: Glass fibre reinforced polymer composite (GFRP), Resin transfer moulding(RTM), Moisture absorption, tensile modulus and Environmental conditions.

\section{Introduction}

Glass fibre reinforced composite materials are low cost, light-weight, better mechanical properties, free from health hazard, and thus have the potential for aircraft, automobile and similar structural application..Recently, glass-fibre -reinforced polymers(GFRP) are being increasingly used in construction applications ranging from seismic retrofit of columns and strengthening of walls, slabs, to new building frames and even bridges because of a number of advantageous characteristics and anticorrosion properties [1 and2].It is also well known that there is a degradation of material property during its service life, as it is often subjected to environments with high temperature and humidity or having a sharp rise and fall of temperature (thermal spikes). The deterioration that occurs is GFRP during the service life is in general, linked to the level of moisture that is absorbed. The absorption of moisture can be attributed largely to the affinity for moisture of specific functional groups of a highly polar nature in the cured resin. The absorption of moisture causes plasticization of the resin to occur with a concurrent swelling and lowering the glass transition temperature of the resin. This adversely effects the fiber-matrix adhesion properties, resulting debonding at fiber/matrix interfaces, micro-cracking in the matrix, fiber fragmentations, continuous cracks and several other phenomena that actually degrades the mechanical property of the composites.

With reference to the work related to Long-Term Deterioration of GFRP in Water and Moist Environment" [3], the results are indicating the effects of water and moisture on the durability of pultruded glass-fibre-reinforced polymers (GFRP) with vinylester resin for applications in normal air conditions. They conducted deterioration tests, including both immersion and atmosphere conditions at various temperatures and found that cracks appear at surface GFRP specimens and The weight decreases were due to the overlay of two different phenomena: the surface treatment oil used as sizing on the glass-fibre cloth, and the remaining styrene within the specimens being dissolved away. On similar way experimental work has been done with polyester -glass fibre reinforced composites. The environmental stress cracking failure due to temperature and moisture has been studied for glass fiber reinforced composites [6]. Moisture does not only affect the adhesive bond of the bonded system in service, but also during the application of FRP on concrete surface. Tests on CFRP bonded to concrete with initially damp surface using a modified cantilever beam indicated reduction in bond strength when compared to specimens with initially dry concrete surface [7]. Since the failure under effect of moisture generally occurs by either concrete delamination or concrete-epoxy interface separation. The effects of variable moisture conditions on the fracture toughness of concrete/FRP bonded system are studied by means 
of the peel and shear fracture toughness determined from the conditioned test specimens. Moisture conditions can result in strength degradation [8]. The objective of this work is to investigate experimentally the moisture absorption evolution of GFRP laminates subjected to different environmental conditions. For this number of specimens are prepared and exposed in different moisture environmental conditions. To know the weight changes of material due to water absorption at room temperature. For this series of experiments are conducted and results are interpreted to know behaviour of the materials under immersion of different moisture environment. .

\subsection{Production of laminates using RTM}

\section{Experimental}

The Resin transfer molding (RTM) machine,(as shown in Fig1) a, closed mould process, consists of resin injection equipment, it has a hollow cylinder fitted with pressure gauge, valve and pressure pump and mould plates. The materials used for GFRP laminates are polyester resin (with density $1.35 \mathrm{~g} / \mathrm{cm}^{3}$ manufactured by Ciba Geigy Ltd. and supplied by Northern polymers New Delhi India) and Glass fiber mats (woven fabric glass fiber with density $450 \mathrm{~g} / \mathrm{cm}^{2}$ manufactured by Saint Gobian Ltd.India) with composition of $60 \%$ matrix (polyester resin) and $40 \%$ of glass fiber. The specifications for the laminate preparation are (i)injection pressures, 30-40 psi. (ii) Curing Temperature - room temperature. The glass fiber mats are placed between the mould plates and clamped before sending the resin. The chemically combined resin that is resin mixed with $2 \%$ of accelerator (cobalt nathylene) and $2 \%$ of catalyst (methyl ethyl keypricperoxide) is poured inside the hollow cylinder through the valve present at top cap and immediately the valve is closed and the air is pumped into hollow cylinder up to maximum pressure of 40Psi. The bottom valve of the cylinder is slowly released so that pressurized chemical resin enters in to the mould and it is spread equally in to all directions. To get a wellshaped laminate allow the mould to be idle for 4 to 5 hours and laminate is solidified then unseal the mould separate the lower and upper mould parts . The laminate is slightly sticky to the mould surface and removed forcibly and laminate of mould shape is as shown fig.2. Since such laminate obtained is difficult to test, and to have moisture test for that laminates are sliced to standard ASTMD638 specimen of dimensions $50 \mathrm{~mm}$ X 30 $\mathrm{mm}$ X $8 \mathrm{~mm} \mathrm{~mm}$.

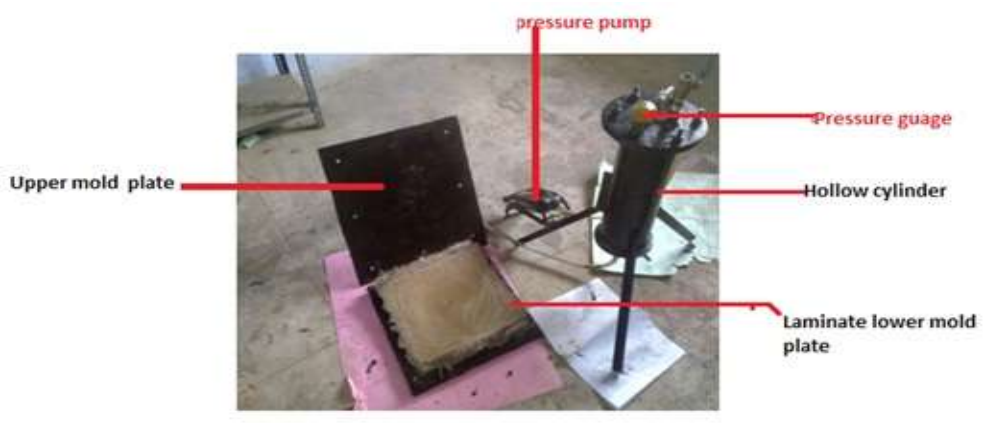

Fig1:RTM with Composite laminate piece

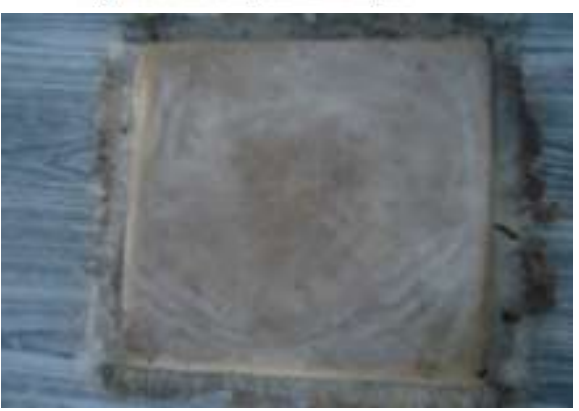

Fig. 2: Composite laminate piece

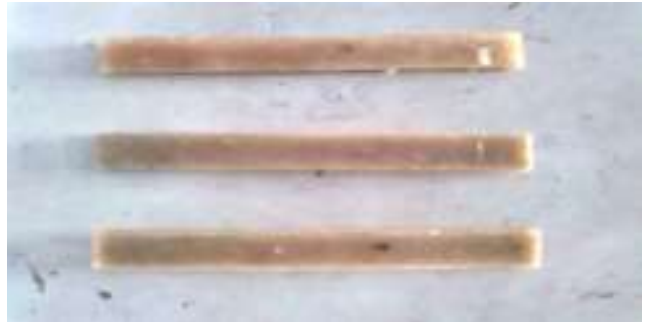

Fig.3 GFRP Composite Laminate 


\subsection{Testing of the Laminates}

The laminates obtained by RTM process are $300 \mathrm{~mm}$ X $300 \mathrm{~mm} \mathrm{X} 8 \mathrm{~mm}$ as shown in the fig. 2 from that standard specimen of dimensions $250 \mathrm{~mm}$ X $30 \mathrm{~mm} \mathrm{X} 8 \mathrm{~mm}$ are prepared (fig.3) and that slice in to size of $50 \mathrm{~mm}$ X $30 \mathrm{~mm}$ X $8 \mathrm{~mm}$. The specimen thus prepared were exposed to several moist environments water, salt water and $\mathrm{NaOH}$ solution for different exposure time. For moisture absorption test, numbers of weighted specimens are exposed in tubs containing water, salt water and $\mathrm{NaOH}$ solution at room temperature for 18 days as shown in fig3. At every 3 days few specimens are taken from water tub, salt water tub and $\mathrm{NaOH}$ tub at room temperature and weighed, the results are noted in tables 1,2 and3. The weight gain (\%)of specimens exposed in different moisture conditions are presented in table4 and plotted the Graph (as shown in graph1).

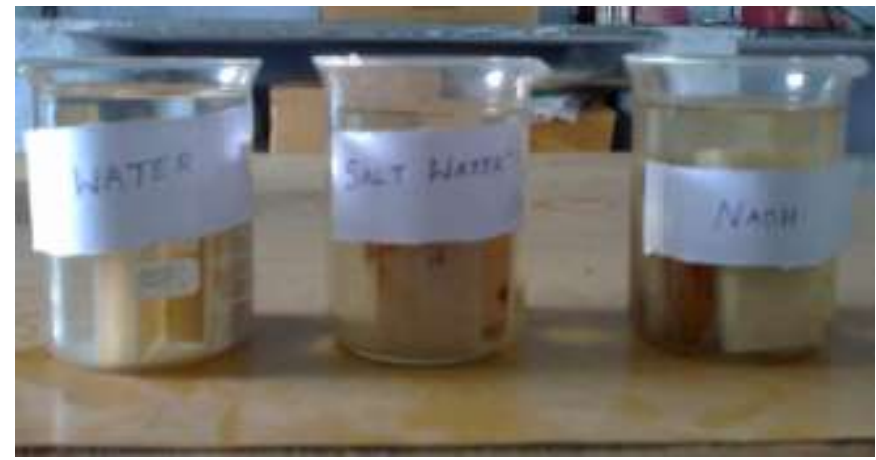

Fig.3:GFRP Specimens exposed in different moisture conditions

\section{Results \& Discussions}

The aim of this work is to investigate the absorption of moisture in E-Glass / polyester resin composites under different moist environmental conditions to understand the overall effect of moisture absorption on the weight and mechanical property. The experimental results are presented in tables 1,2,3 and4.

\subsection{Theory of Moisture Absorption :}

Weight gain of the preconditioned specimens was carefully monitored by weighing multiple specimens periodically, with precautions taken to remove the surface moisture by wiping them before weighing. Percentage weight gain was determined as

$$
\mathrm{M}=\left(\frac{\text { Weight of specimen }- \text { Weight of dry specimen }) X}{\text { (Weight of dry specimen })} 100\right.
$$

As the natural process of moisture absorption in resin matrices is normally very slow, so Fick's second law for a concentration independent moisture diffusion process for a long period of exposure in the solution can be approximated as

$$
M=\{1-8 / p 2 \exp (-p 2 D t / h 2)\} M_{m}(2)
$$

where $\mathrm{D}, \mathrm{t}, \mathrm{h}, \mathrm{M}_{\mathrm{m}}$ are the composite diffusion coefficient, time at maximum moisture content, specimen thickness, and maximum moisture content respectively.

\subsection{Effect of Moisture Absorption on weight and tensile property}

This work focused on the investigation of the effect of moisture impact on GFRP composite laminates under different moisture environmental (water, salt water \& $\mathrm{NaOH}$ solution) conditions. The test results are analysed the relations of weight gain verses exposure time and tensile modulus verses exposure time were plotted at various water salinity conditions as shown in graphs 1and 2. The test results shows moisture absorbed is different for different environmental conditions, it is clear that the weight gain is more in water than $\mathrm{NaOH}$ and salt water respectively. The reasons are all the voids of laminates filled rapidly in water than $\mathrm{NaOH}$, saltwater due to capillary action and water seepage into fiber-matrix inter-phase .The way of moisture absorbed is dependent upon many factors like type of climatic exposure, severity of exposure humidity and temperature. The effect of moisture absorption on weight gain for the E-Glass/polyester resin composite material as shown in graph1. It can be observed that initially, there is almost a linear increase in the equilibrium moisture content, then after gradually increases and expected to approaches constant saturation level. From graph2,it was observed that tensile modulus decreased to some extent with the presence of moisture. Strains are parallel and transverse to the fibres at functional failure (leakage) showed a little variation in the presence of moisture at room temperature. The effective water damage was apparent in the matrix and at the fibre-matrix interface where there was less resin adhesion to the fibres with increasing exposure time. Fibre 
Moisture Absorption Evolution Of Gfrp Laminate Subjected To Different Environmental Conditions strength was also negatively affected, possibly due to either leaching out of the glass fibres interface layer or glass fibre embrittlement, less effective bonding and load distribution at the fibre-matrix interface.

\subsubsection{Effect of water on tensile modulus}

The tensile strength of GFRP laminates exposed to water at room temperature is decreases gradually over exposure period of 18 days after continuous exposure the reduction of tensile modulus expected to maintain constant. The reasons can be initially rapid entering of water particles into fibre- matrix interface due to capillary action. After certain period of time, a saturation stage is reached and no more water seep into fibrematrix phase .All the voids of laminates filled with moisture and which act as a plasticizer to fevor the property.

\subsubsection{Effect of salt water on tensile modulus}

The tensile strength of GFRP laminates exposed to salt water at room temperature is decreases gradually. For same exposure period, reduction of the tensile modulus is more in salt water compare to water. The reasons are matrix swelling and debonding fibre-matrix interface are more effective in saltwater.

\subsubsection{Effect of $\mathrm{NaOH}$ on tensile modulus}

The tensile strength of GFRP laminates exposed to $\mathrm{NaOH}$ solution at room temperature is decreases with exposure time. The reduction in strength due to attack of $\mathrm{NaOH}$ base on polyester resin. The base solution react with polyester resin surface and erodes it. Finally concluded that $\mathrm{NaOH}$ base deteriorates surface the composite material and leads to reduction in the strength.

Table 1 : specimens exposed to water Specimen exposed in water

\begin{tabular}{|c|c|c|c|c|c|c|c|}
\hline \multirow{3}{*}{ Specimen no } & \multicolumn{7}{|c|}{ Specimen exposed in water } \\
\hline & \multicolumn{7}{|c|}{ Weights of specimen in grams with exposure time } \\
\hline & $\mathbf{0}$ & 3 days & 6 days & 9 days & 12 days & 15 days & 18days \\
\hline 1 & $\mathbf{1 7 . 7}$ & 18.4 & 19.2 & 19.6 & 19.8 & 19.9 & 20.2 \\
\hline 2 & 18.9 & 20.5 & 21.6 & 22.1 & 22.4 & 22.6 & 22.8 \\
\hline 3 & 19.0 & 19.8 & 20.8 & 21.9 & 22.2 & 22.4 & 22.6 \\
\hline 4 & 19.4 & 20.2 & 20.8 & 21.3 & 21.9 & 22.2 & 22.4 \\
\hline 5 & 19.6 & 20.6 & 21.2 & 21.6 & 22.0 & 22.4 & 22.5 \\
\hline Total wt & 93.6 & 99.5 & 103.6 & 106.5 & 108.3 & 109.5 & 110.5 \\
\hline \% of wt. gain & $\mathbf{0}$ & 6.3034 & 10.6837 & 13.7820 & 15.7051 & 16.9871 & 18.0555 \\
\hline
\end{tabular}

Table2: specimens exposed to salt water

\begin{tabular}{|l|l|l|l|l|l|l|l|}
\hline \multicolumn{7}{|c|}{ Specimen exposed in salt water } \\
\hline Specimen no & \multicolumn{7}{|c|}{ Weights of specimen in grams with exposure time } \\
\cline { 2 - 9 } & 0 & 3 days & 6 days & $\mathbf{9}$ days & 12 days & 15 days & $18 d a y s$ \\
\hline 1 & 17.3 & 17.9 & 18.6 & 19.3 & 19.5 & 19.7 & 19.9 \\
\hline 2 & 18.4 & 19.2 & 20.6 & 21.1 & 21.8 & 22.0 & 22.2 \\
\hline 3 & 22.8 & 23.4 & 23.8 & 23.1 & 23.4 & 23.8 & 24.1 \\
\hline 4 & 20.3 & 20.9 & 22.0 & 22.3 & 22.6 & 22.8 & 23.1 \\
\hline 5 & 19.6 & 20.5 & 21.0 & 21.4 & 21.8 & 22.1 & 22.4 \\
\hline Total wt & 98.4 & 101.9 & 106.0 & 107.2 & 109.1 & 110.4 & 111.7 \\
\hline \%of wt.gain & 0 & 3.5569 & 7.7235 & $\mathbf{8 . 9 4 3 0}$ & 10.8739 & 12.1951 & 13.5162 \\
\hline
\end{tabular}

Table.3 Specimen exposed in $\mathrm{NaOH}$ solution

\begin{tabular}{|c|c|c|c|c|c|c|c|}
\hline \multicolumn{8}{|c|}{ Specimen exposed in $\mathrm{NaOH}$ solution } \\
\hline \multirow{2}{*}{ Specimen no } & \multicolumn{7}{|c|}{ Weights of specimen in grams with exposure time } \\
\hline & $\mathbf{0}$ & 3 days & 6 days & 9 days & 12 days & 15 days & 18days \\
\hline 1 & 17.3 & 19.0 & 18.5 & 19.1 & 19.8 & 20.3 & 20.6 \\
\hline 2 & 21.3 & 22.2 & 22.8 & 23.4 & 23.9 & 24.3 & 24.6 \\
\hline 3 & 22.0 & 23.1 & 23.9 & 24.5 & 24.9 & 25.3 & 25.6 \\
\hline 4 & 21.9 & 22.6 & 22.9 & 23.3 & 23.9 & 24.1 & 24.2 \\
\hline 5 & 19.6 & 20.4 & 21.0 & 21.6 & 22.0 & 22.4 & 22.5 \\
\hline Total wt & $\mathbf{1 0 2 . 1}$ & 107.3 & 109.1 & 111.9 & 114.5 & 116.4 & 117.5 \\
\hline \%of wt. gain & $\mathbf{0}$ & 5.093 & 6.8560 & 9.5984 & 12.1449 & $\mathbf{1 4 . 0 0 5 8}$ & 15.0832 \\
\hline
\end{tabular}


Moisture Absorption Evolution Of Gfrp Laminate Subjected To Different Environmental Conditions

Table 4 : The weight gain (\%) and tensile modulus of specimens exposed in different moisture conditions

\begin{tabular}{|l|l|l|l|l|l|l|}
\hline \multirow{2}{*}{$\begin{array}{l}\text { Exposure } \\
\text { time } \\
\text { In days }\end{array}$} & \multicolumn{3}{l}{$\begin{array}{l}\text { Weight gain in different moisture } \\
\text { conditions }\end{array}$} & $\begin{array}{l}\text { Variation in tensile modulus in } \\
\text { different }\end{array}$ \\
\cline { 2 - 7 } & Water & Salt water & $\mathrm{NaOH}$ & Water & Salt water & $\mathrm{NaOH}$ \\
\hline 0 & 0 & 0 & 0 & 0.97 & 0.97 & 0.97 \\
\hline 3 & 6.3034 & 3.5569 & 5.0930 & 0.964 & 0.960 & 0.950 \\
\hline 6 & 10.6837 & 7.7235 & 6.8560 & 0.952 & 0.942 & 0.925 \\
\hline 9 & 13.7820 & 8.9430 & 9.5984 & 0.945 & 0.936 & 0.911 \\
\hline 12 & 15.7051 & 10.8739 & 12.1449 & 0.924 & 0.920 & 0.901 \\
\hline 15 & 16.9871 & 12.1951 & 14.0058 & 0.913 & 0.886 & 0.868 \\
\hline 18 & 18.0555 & 13.5162 & 15.0832 & 0.902 & 0.878 & 0.857 \\
\hline
\end{tabular}

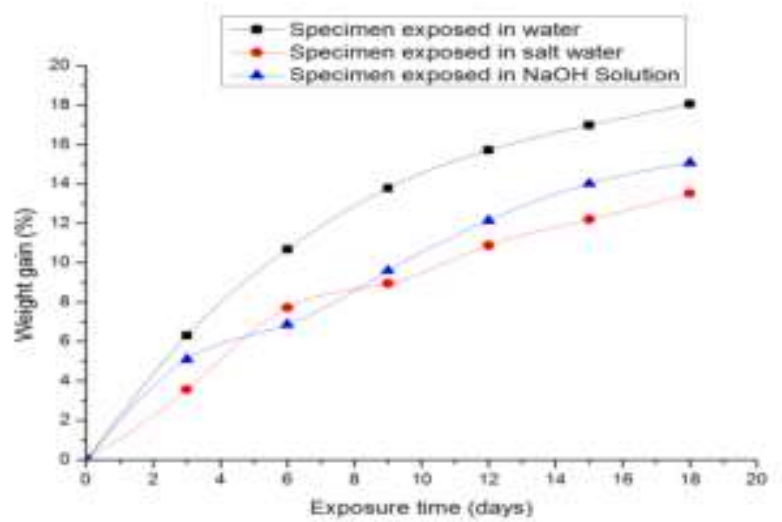

Graph1: Weight gain V/S Exposure time for Specimens exposed in different moisture conditions

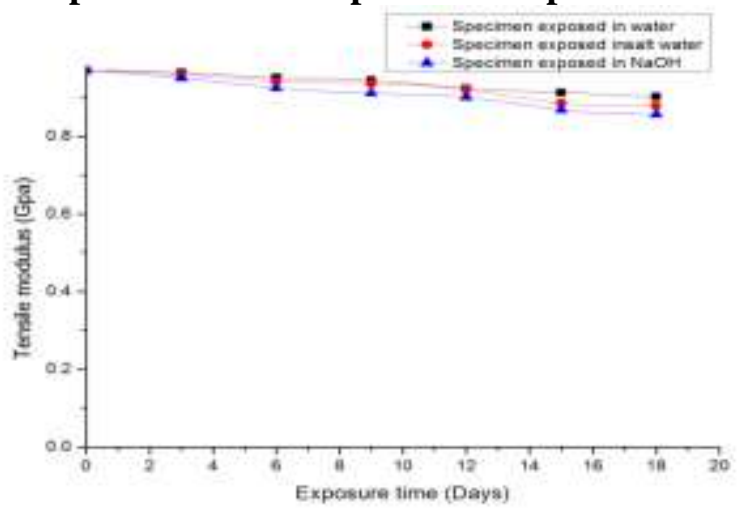

\section{Graph2: Tensile modulusV/S Exposure time for Specimens exposed in different moisture conditions}

\section{Conclusions}

The experimental investigation showed effect of moisture absorption and remarkable reduction in mechanical strength (tensile modulus) of GFRP Composites which are exposed to different water salinity and at room temperature for different exposure time. The experimental results shows weight gain and reduction in tensile modulus of GFRP Specimens in order of water, $\mathrm{NaOH}$ and salt water. The moisture present in matrix of composite material causes matrix swelling, inter-phase debonding, physical damage of matrix inter-phase and hydrolysis of composite materials are the main reasons for the reduction in tensile strength. The following conclusions may be drawn for this study:

i The Composite material moisture absorption is more.

ii. The presence of moisture or water particles in the matrix, fiber-matrix interface of composite materials attack on the glass fibres, all these are the reason for the reduction of mechanical properties. But in both normal and frozen conditions the damage is more severe in case of frozen moisture. 
iii. The weight gain of laminate is more in water by reasons of capillary action, wicking action less concentration and density as compare to salt water and $\mathrm{NaOH}$ solution.

iv. Debonding at the fiber/matrix interface in a fiber bundle is caused after the amount of absorbed moisture reaches to a saturation level, and as a result the tensile elastic modulus remains constant.

\section{References:}

[1] Busel, J. P. FRP composites in construction application-A profile in progress, SPI Composite Institute-1995

[2] Meiarashi, S., Kishima, T., Nishizaki, I., and Sasaki, I. "Application of fiber reinforced plastics to construction structural materials. Volume 1:.' Cooperative Research Report No. 252, 1998

[3] Nishizaki and Meiarashi,S (2002) Long term Deteration GFRP in Water and Moist Environment Journal of Composite for Construction, Vol.6 NO.1 PP21-27.

[4] Moisture Absorption and Desorption of Composite Materials" by author Chi-Hung shen and George S. Springer journal of composite materials january1976]

[5] The "Durability of bamboo-glass fiber reinforced polymer matrix hybrid composites" by author MOE MOE THWE, KIN LIO publised in journal of Composites Science and Technology 63 (2003) 375-387

[6] The environmental stress corrosion cracking of glass fibre-reinforced laminates and single E-glass filaments by author F.R.JONES. J.W.ROCK, J.E.BAILEY (19833)1059-1071

[7] Wan B, Petrou MF, Harries KA. The effects of the presence of water on the durability of bond between CFRP and concrete. J Reinf Plast Composites 2006; 25(8):875-90.

[8] C.Tukta and O.Buyukozturk on the "Deterioration of FRP/concrete bond system under variable moisture conditions quantified by fracture mechanic Composites: PartB 42(2011)145-154 Elsevier.

[9] Long-term water immersion ageing characteristics of GFRP composites by K.Berketis publised in journal of springerScience+Business2009.

[10] Mechanical testing of advanced fibre composites J M Hodgkinson Wood Head Publishng Limited.

[11] Springer G.S.,Environmental ffects on Composite materials Vol.2 (1984), Lancaster PA:Technomic publishing co.inc. 